\title{
Effect of Ampicillin, Cefmetazole and \\ Minocycline on the Adherence of Branhamella catarrhalis to Pharyngeal Epithelial Cells
}

\author{
Kamruddin Ahmed, Keizo Matsumoto, Naoto Rikitomi, \\ Tsuyoshi Nagatake, Toshiaki Yoshida and Kiwao \\ Watanabe \\ Department of Internal Medicine, Institute of Tropical \\ Medicine, Nagasaki University, Nagasaki 852
}

\begin{abstract}
Ahmed, K., Matsumoto, K., Rikitomi, N., Nagatake, T., Yoshida, T. and Watanabe, K. Effect of Ampicillin, Cefmetazole and Minocycline on the Adherence of Branhamella catarrhalis to Pharyngeal Epithelial Cells. Tohoku J. Exp. Med., 1990, 161 (1), 1-7 _ U Using pharyngeal epithelial cells from a healthy adult and eight strains of Branhamella catarrhalis (B. catarrhalis) isolated from eight patients with respiratory infection the effect of subminimal inhibitory concentrations of cefmetazole, ampicillin and minocycline on adherence was examined. Cefmetazole-treated bacterial attachment $(44 \pm 28$; mean \pm s.D. $)$ decreased significantly $(p<0.05)$ compared to the control $(84 \pm 27)$. Statistically no significant difference in adherence was found between ampicillin-treated bacteria $(63 \pm 36)$ and the control $(95 \pm 40)$ or minocycline-treated bacteria $(91 \pm 39)$ and the control $(109 \pm 40)$. Large bacteria was observed after cefmetazole and ampicillin treatment. In addition to diplococci, tetrads were observed after cefmetazole treatment. Significant correlation between the MICs and adherence ability was not found. The results suggests that these three antibiotics were not responsible for the increase in $B$. catarrhalis infection by increasing adherence ability. - Branhamella catarrhalis; antibiotics; adherence
\end{abstract}

In recent years evidence has accumulated to suggest that the initial event in colonization and invasion is the adherence of the microorganism to the epithelial cells of the mucosal surface of respiratory, gastrointestinal and urogenital tracts (Ofek et al. 1979). Bacterial adherence on the surface of oral mucosa has been regarded as an important factor for pathogenic bacteria to invade lower respiratory tract (Johanson et al. 1979). It has been recently reported that there is a significant correlation between the occurrence of infection and the adherence ability of $B$. catarrhalis to oropharyngeal cells from patients with respiratory diseases (Mbaki et al. 1987). Several investigators (Ninane et al. 1978 ; Johnson et al. 1981 ; Matsumoto 1981; McLeod et al. 1983) reported that B. catarrhalis has become an important respiratory pathogen. The reason for increase in the inci-

Received December 14, 1989; revision accepted for publication February 27, 1990. 
dence of respiratory infections caused by $B$. catarrhalis has not been clearly understood. Among many factors, antibiotics are considered to be responsible for the increasing incidence in B. catarrhalis infections (Waters et al. 1985 ; McLeod et al. 1986). Subminimal inhibitory concentrations (sub-MICs) of antibiotic may reach the mucosal surface intermittently during the course of therapy and thereby interfere with the ability of microorganisms to colonize (Ofek et al. 1979). Moreover, the ability of antibiotics to affect the property of microbial adherence to cell surfaces may be an important criterion for selecting an antibiotic for therapy (Shibl 1985) and small dose prophylaxis to prevent bacterial colonization (Sandberg et al. 1979).

Because of the increasing importance of $B$. catarrhalis respiratory infections it is important to examine the effect of antibiotics as to its adherence and colonization. Ampicillin and cefmetazole are widely-used $\beta$-lactam antibiotics. However, ampicillin is inactivated by $\beta$-lactamase of $B$. catarrhalis, whereas cefmetazole is active against the organism. Minocycline has a different mechanism of action and is potent against $B$. catarrhalis. Therefore, the effects of ampicillin, cefmetazole and minocycline on the adherence of $B$. catarrhalis to oropharyngeal cells were studied in the present study.

\section{Materials And Methods}

Bacterial strains. Eight strains of $B$. catarrhalis were isolated from eight patients with respiratory infection and were kept at $-40^{\circ} \mathrm{C}$ in Brain Heart Infusion broth (BBL Microbiology System; Becton Dickinson and Company, Cockeysville, MD, USA) containing $5 \%$ horse blood until use.

Determination of minimal inhibitory concentrations (MICs). The susceptibility of the strains for ampicillin, cefmetazole and minocycline was determined by the serial two-fold agar dilution method with an inoculum of $10^{6}$ colony forming units (cfu) $/ \mathrm{ml}$. Trypticase Soy Agar (TSA, BBL Microbiology Systems; Becton Dickinson and Company) containing $5 \%$ horse blood was used as the test medium. MICs were defined as the lowest concentrations of antibiotic that prevented visible growth after overnight incubation at $37^{\circ} \mathrm{C}$ in a $\mathrm{CO}_{2}$ incubator.

Determination of $\beta$-lactamase production. $\beta$-Lactamase production was examined with the Betalactam Reagent Disc (Marion Scientific, Kansas City, MO, USA) and Cefinase TM disc (BBL, Microbiology Systems, Becton Dickinson and Company).

Treatment of bacteria with sub-MIC of antibiotics. Bacteria were treated by culturing on media containing one of the three antibiotics (ampicillin, cefmetazole and minocycline) at a concentration of $1 / 4$ MIC. When bacteria did not grow or had severely damaged morphology at $1 / 4$ MIC, a concentration of $1 / 8$ MIC was used. Bacteria grown on media containing no antibiotics was used as control. In all cases TSA media containing $5 \%$ horse blood and an inoculum of $10^{6} \mathrm{cfu} / \mathrm{ml}$ was used and then incubated for $18 \mathrm{hr}$ at $37^{\circ} \mathrm{C}$ in a $\mathrm{CO}_{2}$ incubator.

Determination of viable bacteria. After the above treatment, with or without antibiotic bacteria were suspended in PBS (phosphate buffer saline) and the viable count determined. Adherence assay was done using these bacterial suspensions. For viable counting tenfold serial dilution of bacterial suspension was made in physiologic saline.

Microscopic appearence of bacteria. Comparison of appearence between the antibiotic treated and the untreated bacteria was microscopically done after Gram-staining. 
Oropharyngeal cells. By scraping the oropharynx of a volunteer with a cotton-tipped swab, oropharyngeal cells were collected and then dislodged by twirling the swab in $4 \mathrm{ml}$ of divalent cation-free PBS.

Bacterial adherence assay. Adherence assay was done by the method previously described (Mbaki et al. 1989). The number of adherent B. catarrhalis was determined after 50 consecutive epithelial cell counts. In each experiment, antibiotic-treated bacterial adherence was compared to identically handled control bacteria.

Electron microscopy. B. catarrhalis was cultured on TSA media containing $5 \%$ horse blood with and without cefmetazole and was incubated in a $\mathrm{CO}_{2}$ incubator at $37^{\circ} \mathrm{C}$ for 18 hr. Specimen preparation for electron microscopy was done by the freeze-substitution method (Osumi et al. 1988) with the following modification : (i) Copper plate $(9 \times 2 \times 0.03$ $\mathrm{mm}$ ) was used to sandwich bacteria. It was then immersed into nitrogen cooled Freon 22. (ii) Freeze-substitution fluid was $1 \%$ osmium tetroxide. (iii) The specimen was embedded in epoxy resin. Sections were cut with a Reichert Ultra cut $\mathrm{E}$ and stained with $7 \%$ uranyl acetate and lead citrate. Finally after carbon coating, specimens were examined with a JEM $100 \mathrm{CX}$ electron microscope (JOEL Ltd., Tokyo) operated at $80 \mathrm{kV}$.

Statistical analysis. The number of bacteria attached was expressed as mean \pm s.D. To check statistical difference the Student's $t$-test was applied.

\section{Results}

Susceptibility to antibiotics. Table 1 summerizes the MICs of ampicillin, cefmetazole and minocycline against eight strains of $B$. catarrhalis. MICs of seven strains against ampicillin ranged from $0.39 \mu \mathrm{g} / \mathrm{ml}$ to $1.56 \mu \mathrm{g} / \mathrm{ml}$ and one strain was $6.25 \mu \mathrm{g} / \mathrm{ml}$. MICs of all eight strains against cefmetazole and minocycline ranged from $0.39 \mu \mathrm{g} / \mathrm{ml}$ to $1.56 \mu \mathrm{g} / \mathrm{ml}$ and from $0.10 \mu \mathrm{g} / \mathrm{ml}$ to $0.20 \mu \mathrm{g} / \mathrm{ml}$, respectively. All were $\beta$-lactamase producing strains.

Effect of subminimalinhibitory concentrations of antibiotics on adherence. Fig. 1 shows the effect of ampicillin-, cefemetazole- or minocycline-treated bacterial adherence compared to their respective controls. The number of

TABLE 1. Minimal inhibitory concentrations (MICs) of eight strains of Branhamella catarrhalis against ampicillin, cefmetazole and minocycline

\begin{tabular}{|c|c|c|c|c|c|c|c|c|c|}
\hline \multirow[t]{2}{*}{ Strain } & \multirow[t]{2}{*}{ MIC } & \multicolumn{2}{|c|}{$\begin{array}{l}\text { Ampicillin } \\
(\mu \mathrm{g} / \mathrm{ml}) \\
\text { sub-MIC }\end{array}$} & \multirow[t]{2}{*}{ MIC } & \multicolumn{2}{|c|}{$\begin{array}{c}\text { Cefmetazole } \\
(\mu \mathrm{g} / \mathrm{ml}) \\
\text { sub-MIC }\end{array}$} & \multirow[t]{2}{*}{ MIC } & \multicolumn{2}{|c|}{$\begin{array}{l}\text { Minocycline } \\
(\mu \mathrm{g} / \mathrm{ml}) \\
\text { sub-MIC }\end{array}$} \\
\hline & & $1 / 4 \mathrm{MIC}$ & 1/8 MIC & & $1 / 4 \mathrm{MIC}$ & $1 / 8 \mathrm{MIC}$ & & $1 / 4 \mathrm{MIC}$ & $1 / 8 \mathrm{MIC}$ \\
\hline 1 & 1.56 & 0.39 & 0.20 & 0.39 & 0.10 & 0.05 & 0.10 & 0.025 & 0.013 \\
\hline 2 & 1.56 & 0.39 & 0.20 & 0.39 & 0.10 & 0.05 & 0.20 & 0.05 & 0.025 \\
\hline 3 & 1.56 & 0.39 & 0.20 & 1.56 & 0.39 & 0.20 & 0.10 & 0.025 & 0.013 \\
\hline 4 & 1.56 & 0.39 & 0.20 & 0.39 & 0.10 & 0.05 & 0.10 & 0.025 & 0.013 \\
\hline 5 & 0.78 & 0.20 & 0.10 & 0.39 & 0.10 & 0.05 & 0.10 & 0.025 & 0.013 \\
\hline 6 & 1.56 & 0.39 & 0.20 & 0.39 & 0.10 & 0.05 & 0.10 & 0.025 & 0.013 \\
\hline 7 & 0.39 & 0.10 & 0.05 & 0.39 & 0.10 & 0.05 & 0.10 & 0.025 & 0.013 \\
\hline 8 & 6.25 & 1.56 & 0.78 & 1.56 & 0.39 & 0.20 & 0.10 & 0.025 & 0.013 \\
\hline
\end{tabular}




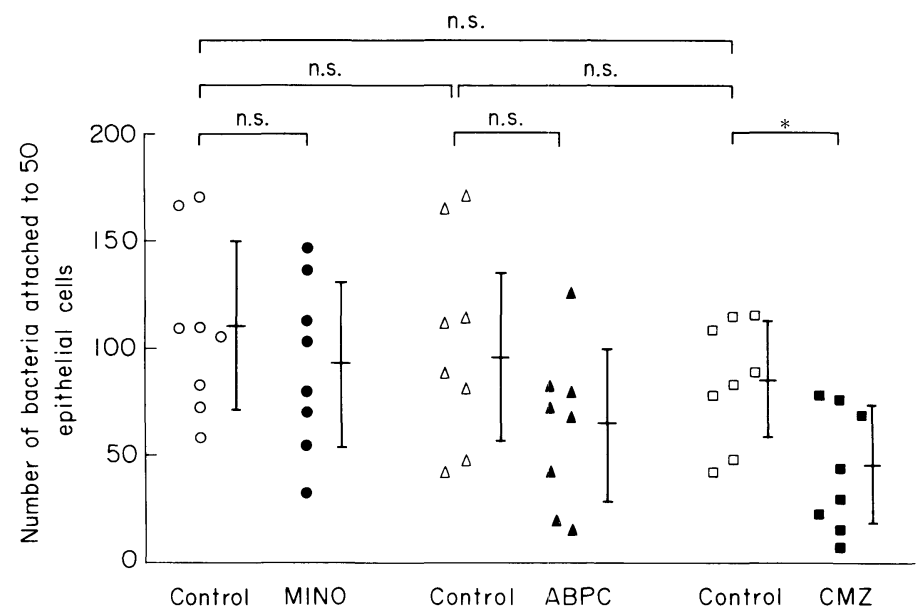

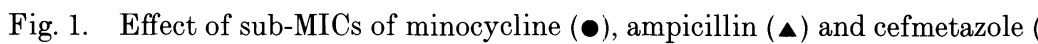
on the adherence of Branhamella catarrhalis to human pharyngeal epithelial cells compared with their corresponding control $(\circ, \triangle, \square)$. n.s., not significant ; ${ }^{*} p<0.05$.

cefmetazole-treated bacterial attachment $(44 \pm 28)$ decreased significantly $(p<$ $0.05)$ compared to the control $(84 \pm 27)$, whereas there was no significant difference in bacterial attachment between ampicillin-treated bacteria $(63 \pm 36)$ and its control $(95 \pm 40)$. There is also no significant difference between minocycline-

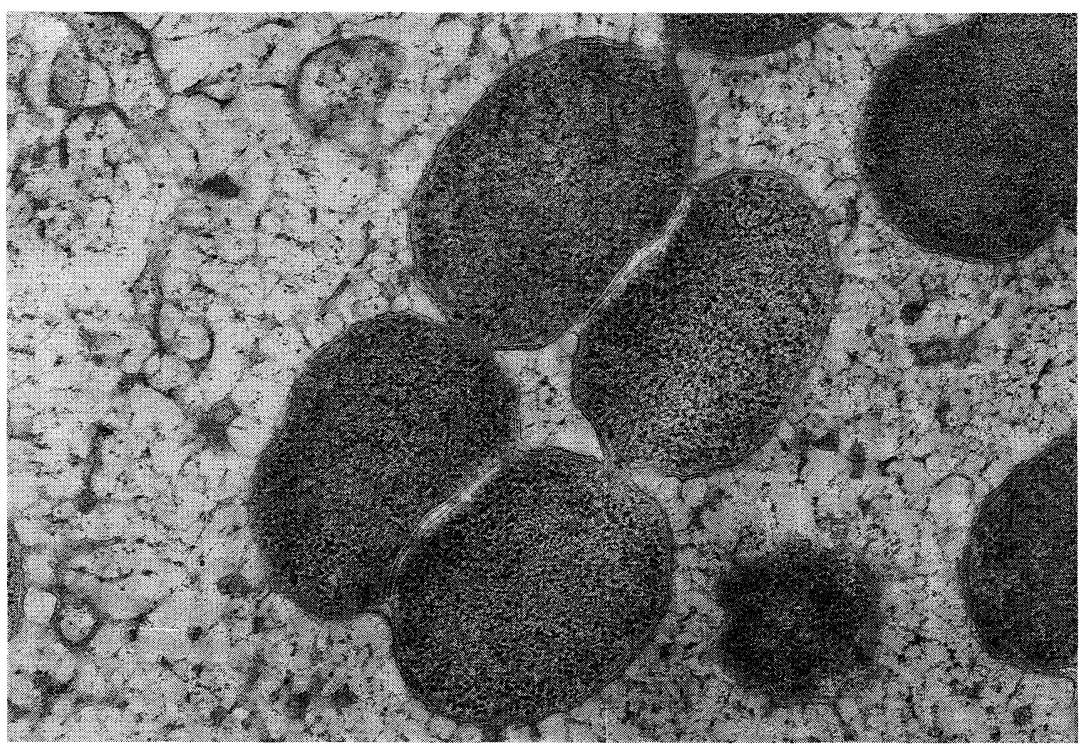

Fig. 2. Branhamella catarrhalis treated with sub-MIC of cefmetazole as viewed under the light microscope. Diplococci, tetrads and few disrupted bacteria are seen $(\times 850)$. 


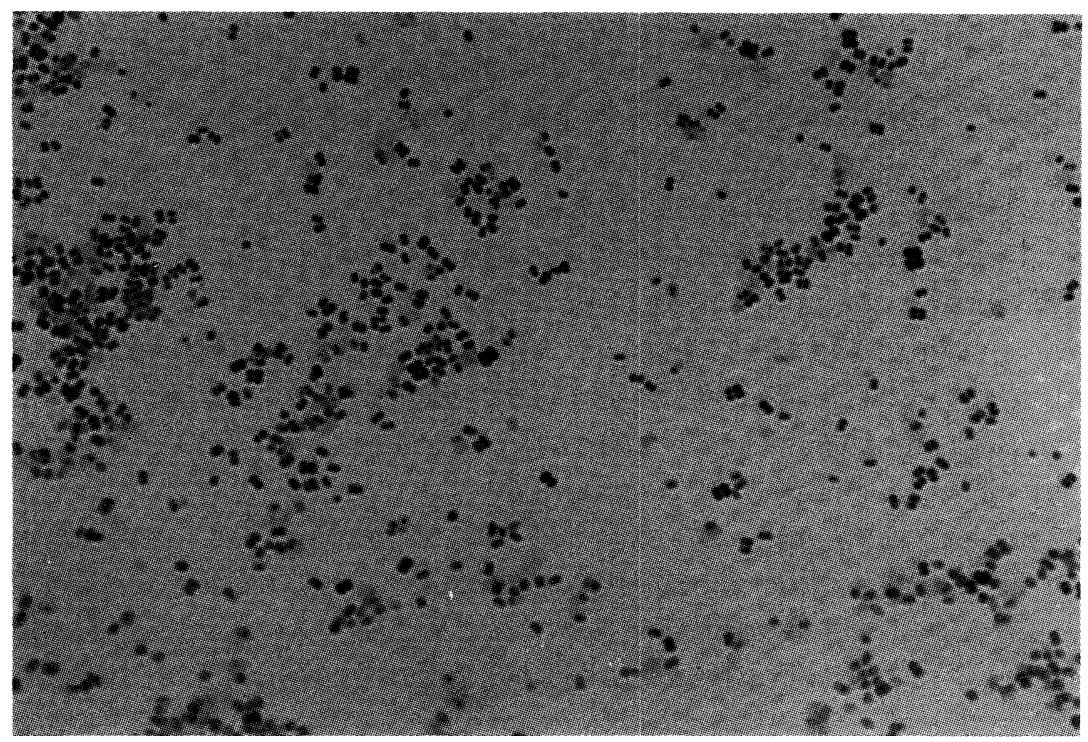

Fig. 3. Tetrads formed after treatment with sub-MIC of cefmetazole as viewed under the transmission electron microscope $(\times 19,000)$.

treated bacterial attachment $(91 \pm 39)$ and its control $(109 \pm 40)$. The coefficient variance $(\mathrm{CV})$ of attached bacteria is $63 \%$ and $32 \%$ for cefmetazole-treated bacteria and its control; $57 \%$ and $42 \%$ for ampicillin-treated bacteria and its control ; $42 \%$ and $36 \%$ for minocycline-treated bacteria and its control, respectively.

Microscopic appearance of bacteria. Ampicillin treatment in some instances was associated with the development of large bacteria. Cefmetazole also caused large bacteria. In addition to diplococci, tetrads and some bacterial clumps were observed in some instances. Moreover, some of the bacteria were disrupted (Fig. 2). However, changes could not be detectable after treatment with minocycline.

Correlation between susceptibility and adherence. No correlation was found between MIC and adherence of antibiotic-treated or untreated bacteria (data not shown).

Electron microscopic observation. After sub-MIC treatment of cefmetazole, abnormal findings were observed in the cell wall of some bacteria. The tetrads were formed due to inability of the daughter cells to separate from the parent cells (Fig. 3).

\section{Discussion}

In the present study it was proved that at sub-MIC, cefmetazole significantly decreased the adherence ability of $B$. catarrhalis to human pharyngeal epithelial cells, while ampicillin or minocycline-treated $B$. catarrhalis had no effect on adherence. Previously it has been reported that the adherence ability to human 
uroepithelial cells and oropharyngeal cells decreased in ampicillin-treated Escherichia coli (E. coli) (Sandberg et al. 1979) and Neisseria meningitidis (Salit 1983), respectively. Furthermore another researcher reported that ampicillin treated $E$. coli had no effect on a human epitheloid tissue culture cell line that had a similar property to human epithelial cells (Vosbeck et al. 1979). The different adherence ability of ampicillin-treated bacteria to epithelial cells may depends upon the growth condition, period of incubation, different assay system or different bacterial strains even in the same system (Vosbeck et al. 1979). In comparison with ampicillin, cefmetazole is more stable to $\beta$-lactamase. Therefore in the present study no significant effect on $B$. catarrhalis adherence after ampicillin treatment might be due its instability to $\beta$-lactamase.

Morphological changes were detected after ampicillin and cefmetazole treatment, although after minocycline treatment there was no change in the bacteria. It is assumed that the large size of the bacteria after cefmetazole and ampicillin treatment was due to defective cell wall synthesis. Disruption of bacteria after cefmetazole treatment might be due to its greater stability to $\beta$-lactamase, but the mechanism of tetrad formation is not known. It was noted that large bacteria and tetrads attached less than bacteria of normal morphology.

There was no correlation between MIC and adherence capacity of antibiotictreated and untreated bacteria in this study. The coefficient variance of attachment of antibiotic-treated bacteria and their control to epithelial cells ranged from $42 \%$ to $63 \%$ and $32 \%$ to $42 \%$, respectively. These large coefficient variances, indicate variation in the adhering ability of different isolates of $B$. catarrhalis.

In the present study cefmetazole, ampicillin and minocycline treatment did not increase the bacterial adherence. From the finding it may be assumed that these three antibiotics were not directly responsible for the recent increase of $B$. catarrhalis infections by increasing adhesion, a property that is a potential factor in their pathogenesis. A recent study suggests that nosocomial infections with $B$. catarrhalis were not associated with the use of antibiotics (Cook et al. 1989). It is not known why cefmetazole decreases the adherence capacity of $B$. catarrhalis to pharyngeal cells, there is a possibility that cefmetazole interferes specifically with the formation or expression of adhesin of $B$. catarrhalis. The surface component of $B$. catarrhalis that participates in the adherence process is not yet recognized. Therefore, we did not try to observe the adherence ability and expression of the adhesin during bacterial growth cycle or cell wall synthesis cycle. The inhibitory effect of cefmetazole on $B$. catarrhalis adherence clearly requires further studies.

\section{Acknowledgments}

We thank Miss Miwa Nakayama for technical assistance and Mr. Akitoyo Ichinose for assistance in electron microscopy. 


\section{References}

1) Cook, PP., Hecht, D.W. \& Snydman, D.R. (1989) Nosocomial Branhamella catarrhalis in a paediatric intensive care unit: Risk factors for disease. J. Hosp. Infec., 13, 299-307.

2) Johanson, W.G., Woods, D.E. \& Chaudhuri, T. (1979) Association of respiratory tract colonization with adherence of gram-negative bacilli to epithelial cells. $J$. Infect. Dis., 139, 667-673.

3) Johnson, M.A., Drew, W.L. \& Roberts, M. (1981) Branhamella (Neisseria) catarrhalis a lower respiratory tract pathogen? J. Clin. Microbiol., 13, 1066-1069.

4) Matsumoto, K. (1981) Branhamella catarrhalis infection in chronic respiratory infection. Jap. Med. J., 2961, 31-40. (Japanese)

5) Mbaki, N., Rikitomi, N., Nagatake, T. \& Matsumoto, K. (1987) Correlation between Branhamella catarrhalis adherence to oropharyngeal cells and seasonal incidence of lower respiratory tract infections. Tohoku J. Exp. Med., 153, 111-121.

6) Mbaki, N., Rikitomi, N. Akiyama, M. \& Matsumoto, K. (1989) In vitro adherence of Streptococcus pneumoniae to oropharyngeal cells : Enhanced activity and colonization of the upper respiratory tract in patients with recurrent respiratory infections. Tohoku J. Exp. Med., 157, 345-354.

7) McLeod, D.T., Ahmad, F., Power, J.T., Calder, M.A. \& Seaton, A. (1983) Bronchopulmonary infection due to Branhamella catarrhalis. Br. Med. J., 287, 14461447.

8) McLeod, D.T., Ahmad, F., Capewell, S., Crougham, M.J., Calder, M.A. \& Seaton, A. (1986) Increase in bronchopulmonary infection due to Branhamella catarrhalis. $\mathrm{Br}$. Med. J., 292, 1103-1105.

9) Ninane, G., Joly, J. \& Kraytman, M. (1978) Bronchopulmonary infection due to Branhamella catarrhalis : 11 cases assessed by transtracheal punture. Br. Med. J., 1, $276-278$.

10) Ofek, I., Beachey, E.H., Eisenstein, B.I., Alkan, M.L. \& Sharon, N. (1979) Suppression of bacterial adherence by sub-minimal inhibitory concentrations of $\beta$-lactam and aminoglycoside antibiotics. Rev. Infect. Dis., 1, 832-837.

11) Osumi, M., Baba, M., Naito, N., Taki, A., Yamada, N. \& Nagatani, T. (1988) High resolution, low voltage scanning electron microscopy of uncoated yeast cells fixed by the freeze-substitution method. J. Electron Microsc., 37, 17-30.

12) Salit, I.E. (1983) Effect of subinhibitory concentration of antimicrobials on meningococcal adherence. Can. J. Microbiol., 29, 369-376.

13) Sandberg, T., Stenqvist, K. \& Svanborg-Eden, C. (1979) Effects of subminimal inhibitory concentrations of ampicillin, chloramphenicol and nitrofurantoin on the attachment of Escherichia coli to human uroepithelial cells in vitro. Rev. Infect. Dis., 1, 838-844.

14) Shibl, A.M. (1985) Effect of antibiotics on adherence of microorganisms to epithelial cell surfaces. Rev. Infect. Dis., 7, 51-65.

15) Vosbeck, K., Handschin, H., Menge, E.B. \& Zak, O. (1979) Effects of subminimal inhibitory concentrations of antibiotics on adhesivness of Escherichia coli in vitro. Rev. Infect. Dis., 1, 845-851.

16) Waters, M.J., Steinfort, C.L. \& Andrew, J.H. (1985) Branhamella catarrhalis, a respiratory tract pathogen. Aust. NZ. J. Med., 15, 579-584. 